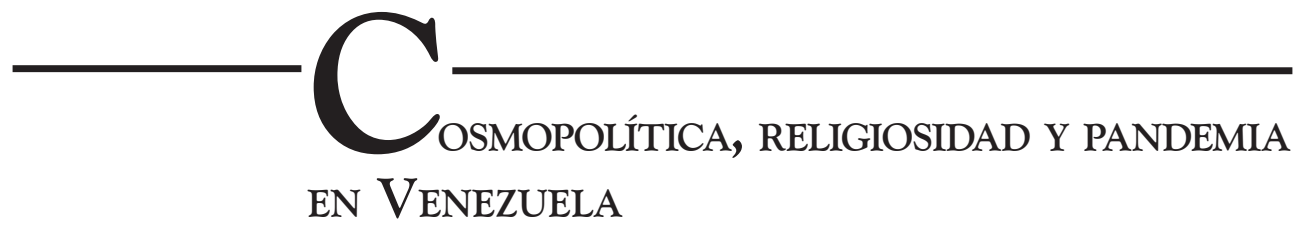

Luis Alonso Hernández

CONICET-UNSAM

Buenos Aires - Argentina

Orcid: https://orcid.org/0000-0003-3447-7061

\title{
El estado de alarma
}

Ante los primeros casos de Covid-19 en Venezuela, el gobierno de Nicolás Maduro emitió el pasado 13 de marzo del año 2020, el decreto número 4.160 que contempló el "Estado de Alarma", para atender la emergencia sanitaria por Coronavirus. Inicialmente, la medida de cuarentena social colectiva aplicó al Distrito Capital y seis de los 23 estados. Luego, el 17 de marzo, el confinamiento se extendió a todo el país y se adoptaron medidas como el cierre de escuelas, liceos, universidades, centros comerciales, estadios e iglesias, entre otros establecimientos. Solo permanecerían abiertos expendios de alimentos y medicinas en horarios entre 8:00 de la mañana y las 13:00 horas. Para finales de noviembre, el país tenía un poco más de 100 mil casos de Covid-19 confirmados oficialmente y unos 200 fallecidos, la cifra más baja entre los países de Latinoamérica.

Pero el "quedarse en casa" visibilizó aún más las fuertes desigualdades en un país donde la gota de petróleo no llegó a todos por igual. En las zonas más precarias, con familias numerosas, varios niños en edad escolar y espacio físico reducido, el confinamiento lo han vivido como un "verdadero infierno" según relatan algunos interlocutores. El llamado a no salir de las viviendas se agravó con el constante racionamiento de agua, vital para combatir un virus que le teme al lavado de manos. La mayoría de estas viviendas carece de tanques de almacenamiento. A esta situación 
se suman los cortes eléctricos y la falta de conexión a internet, lo que imposibilita el éxito de la "educación a distancia", tan aplaudida por la revolución bolivariana en estos tiempos de pandemia. En estos sectores populares han proliferado altares, con fotos de familiares fallecidos, santos católicos y pequeños bustos de Hugo Chávez, a quien le piden protección para no contagiarse de la Covid-19.

Del otro lado de la ciudad, en las urbanizaciones de clase media, si bien se padecen algunos infortunios de la crisis de servicios públicos en Venezuela, el acceso a determinados aparatos (plantas eléctricas, internet satelital, tanques de agua y por lo general ingresos fijos) el confinamiento es más llevadero y los escolares pueden cumplir a tiempo con sus responsabilidades. Sin embargo, respetando las particularidades, la pandemia cambió hábitos y la forma de llevar la rutina, en un país que ha vivido de cerca la escasez de productos básicos. En plena emergencia por coronavirus, lo urgente no es enfermarse, lo vital es alimentarse, ganarle a la inflación y aferrarse a Dios, a familiares fallecidos, a las ánimas del purgatorio y en algunos casos al propio Hugo Chávez, considerado un santo muy poderoso en sectores populares de la capital venezolana, visibilizando un culto que, aunque marginal (si lo comparamos con otras devociones populares) suma creyentes y refuerza la trayectoria del expresidente como "santo", "ser vergatario" o "muerto milagroso", distintas categorías nativas con la que los creyentes denominan al líder de la revolución bolivariana ${ }^{1}$.

Precisamente, es en uno de los sectores populares más importantes de Caracas, elm23 de enero, donde, a semanas del fallecimiento de Chávez, el 5 de marzo de 2013, se construyó una capilla, a la que acuden personas de toda Venezuela a dar gracias por favores concedidos. Además, muchos de los creyentes lo siguen considerando el presidente desde otro plano, porque "Chávez vive, no ha muerto".

\section{"Revolución socialista, cristiana y chavista"}

El pasado siete de abril de 2020, el presidente Nicolás Maduro, en cadena nacional de radio y televisión indicó que Venezuela tiene los índices más bajos de contagios por la Covid-19, debido a la protección de Hugo Chávez y Jesucristo, tomando en consideración que "el socialismo es el modelo de Cristo y el capitalismo es el modelo del diablo"2. En medio de la presentación del libro "Jesús, aproximación

1 Durante el trabajo de campo en el 23 de enero, epicentro del culto a Hugo Chávez, evidencié entre los creyentes tres categorías para referirse al expresidente como un ser suprahumano (Hernández, 2018). Primeramente, un santo tan oficial como los declarados por el Vaticano, en especial entre mujeres de tradición católica. En segundo lugar, un ser vergatario, que está al lado de Dios con cierta autonomía para actuar en el plano terrenal. El vergatario es una categoría en la que la forma sacralizada de Hugo Chávez tendría independencia para actuar de figuras trascendentes, de acuerdo con la cosmovisión de algunos creyentes, quienes afirman que Chávez fue un ser divino, enviado con licencia para "enderezar" a Venezuela. En vocabulario venezolano vergatario representa a una persona excepcional, fuera de lo normal. La Real Academia Española lo define como un venezolanismo para referirse a alguien que sobresale o destaca por alguna cualidad, sobre todo por su valor o fuerza. Por último, un muerto poderoso, que hace favores pero nada tiene que ver con religiones hegemónicas ni con Dios.

2 El mensaje presidencial fue observado por el investigador durante el mensaje presidencial transmitido ese día en cadena obligatoria de radio y televisión. En este caso, por el canal Venevisión. 
histórica", escrito por un sacerdote católico, refirió a que hay que ser valientes y no tener miedo a la pandemia, pues el país cuenta con protección divina. En medio de este discurso, leyó las cifras de contagios en Ecuador, Brasil, Colombia, Estados Unidos y Europa, dando a entender que las naciones capitalistas padecen una suerte de maldición por no atender las necesidades del pueblo, dando prioridad a los intereses de las fuerzas económicas.

En este contexto, Maduro hizo denuncias de bioterrorismo contra el presidente de Colombia, Iván Duque, quien sería la reencarnación del mal en la región latinoamericana. Recordemos que desde el pasado mes de junio y debido a la expansión de la pandemia, miles de venezolanos que habían migrado a países vecinos comenzaron a retornar cruzando ilegalmente la frontera con Colombia. Se estima que, entre mayo y agosto del año 2020, aproximadamente 250 mil venezolanos pasaron a Venezuela desde el vecino país. Este retorno masivo coincidió con el incremento de contagios de la Covid-19, razón por la cual, el Gobierno de Venezuela consideró que los autobuses que trasladaron a los migrantes hasta el paso fronterizo en Colombia, fueron contaminados con el virus por órdenes de Iván Duque.

Las acusaciones hacia Colombia fueron constantes y coincidieron con mensajes radiales en los que el presidente Nicolás Maduro expresó "Fe en Dios y fuerza para enfrentar la pandemia. La fuerza de todas las religiones del mundo". A su vez, en reiteradas apariciones públicas se reforzó la imagen de Hugo Chávez, quien sigue siendo desde el discurso gubernamental el protector de Venezuela, porque desde la óptica de los creyentes en Chávez, el expresidente no murió, "trascendió y cambió de paisaje", razón por la cual, sigue operando activamente en el mundo de los vivos. En este sentido, los creyentes, a pesar de la cuarentena vigente desde marzo del año 2020, siguieron visitando la capilla consagrada a San Hugo Chávez del 23, ubicada en el sector La Planicie, parroquia 23 de enero, en la ciudad de Caracas.

\section{El culto a Hugo Chávez}

El culto a Hugo Chávez comenzó mucho antes de su muerte. Venezolanos pertenecientes a los sectores populares, lo vieron como un salvador en la década de 1990, años de profunda crisis económica y política. Precisamente, el 4 de febrero de 1992, día en que Chávez dirigió la asonada militar contra el entonces presidente Carlos Andrés Pérez, es interpretado por creyentes como la fecha en la que se materializó la aparición del nuevo Simón Bolívar, del hombre enviado por la divinidad para rescatar a Venezuela del yugo de la oligarquía ${ }^{3}$. Tras su muerte, el cinco de marzo

3 Michael Taussig mientras hizo trabajo de campo en Venezuela relacionado al culto a María Lionza, avisoró tempranamente el culto a Hugo Chávez. Tras la intentona golpista del 4 de febrero de 1992, observó en las calles de Caracas el uso masivo de la siguiente plegaria: "Chávez nuestro que estás en la cárcel, santificado sea tu nombre, venga a nosotros tu pueblo, hágase tu voluntad, la de nuestro país, la de tu Ejército, danos hoy la confianza ya perdida y no perdones a los traidores así como tampoco perdonaremos a los que nos traicionan, no nos dejes caer en la corrupción y líbranos del Presidente. Amén (2015: 128). 
de 2013, el carácter sagrado de Chávez adquirió relevancia entre la población de las barriadas del país, se crearon oraciones propias, estampitas, altares domésticos y la capilla consagrada en su nombre.

Muy cerca de la pequeña capilla se encuentra el icónico Cuartel de la Montaña, instalación militar donde reposan los restos del expresidente. Desde ese lugar dirigió el frustrado golpe de Estado mencionado con anterioridad. La gente visita la tumba, pero está prohibido dejar ofrendas, razón por la cual, los creyentes dejan flores y encienden velas en la capilla, resguardada desde su apertura por Elizabeth Torres. Ella se encarga de mantenerla aseada, guardar las ofrendas y colocar un cafecito todas las mañanas frente al busto del comandante.

Elizabeth pertenece a la Milicia, componente de la Fuerza Armada Nacional conformada por civiles. En la actualidad hace sus guardias militares en el santuario y porta el uniforme militar. Me contó que la capilla es sagrada para los creyentes y que no hacen caso a las críticas que se han elevado contra el culto desde la Conferencia Episcopal Venezolana o las iglesias evangélicas. Alega que la jerarquía católica se ha politizado y le hace el juego a la oposición venezolana. "La capilla es un portal para estar en contacto con nuestro comandante eterno y supremo. Chávez es un ser de luz, un ser especial, un enviado divino como Bolívar, es un ser vergatario", me afirmó en una de nuestras conversaciones.

Regularmente visitan la capilla, creyentes en los poderes "suprahumanos" de Chávez. A estas personas las denomino devotos/solicitantes, categoría que uso tomando en cuenta que no buscan la salvación eterna, sino solucionar aspectos rutinarios de la vida que la propia revolución bolivariana tiene dificultades para resolver. Es decir, es un vínculo inmanente con la deidad, que nada tiene que ver con los conceptos de religión cívica. Por lo general, acuden a la capilla para formalizar una petición, dejar ofrendas por favores concedidos, prender una vela o sencillamente tocar el busto del comandante, del cual "brota una energía inexplicable".

También le visitan simpatizantes y curiosos. En enero de 2018 una pareja de turistas argentinos dejó en la capilla una bandera albiceleste y pidió perdón al comandante Chávez, por el triunfo de Mauricio Macri en los comicios de 2015. Hoy día, sigue subiendo gente de otros barrios de Caracas, a pedir favores relacionados a la adquisición de viviendas, trabajo y sobre todo salud. En las visitas hechas a la parroquia 23 de enero durante las semanas en que el gobierno venezolano flexibilizó la cuarentena radical por la Covid-194, devotos/solicitantes siguieron visitando la capilla. No en las cantidades observadas en contextos de normalidad, pero creyentes rezan y dan testimonio de los milagros bajo la mediación o accionar de Hugo Chávez.

Tuve Covid, estuve muy grave y definitivamente fui curada por el comandante. Vivo acá en Caracas y era mi deber visitarlo, hacer el

4 Desde mediados de julio del año 2020, el Gobierno de Nicolas Maduro implementó un plan llamado $7+7$, que alterna una semana con restricciones severas y otra con flexibilización en algunos sectores. 
sacrificio, traerle una vela y rezar la oración al comandante Chávez. Es un ser de gloria, un ser divino, un enviado. Desde el paisaje donde está ahora, sigue cumpliendo a su pueblo, porque despertamos gracias a Chávez. El padre de la revolución.

(Testimonio de Ángeles, 65 años, Caracas, 17 de junio de 2020).

Como Ángeles, varios creyentes, en especial mujeres, visitan la capilla durante las semanas de flexibilización, con alguna prenda vestir roja, aretes con la figura de Chávez y hasta tatuajes en brazos y hombros. Algunos testimonios siguen relacionados a curas por la Covid-19 y reiteran discursos presidenciales sobre la responsabilidad de Colombia en el incremento de casos locales.

Fíjese bien, me curé de la enfermedad, por eso vengo a la capilla. Yo viví en Cúcuta por dos años, me fui por a buscar trabajo porque acá la cosa muy jodida, el embargo gringo nos está matando. Pero por la pandemia lo que estaba pasando era hambre pareja mijo allá en Colombia. Me tuve que venir, pero estoy segura que, ese autobús en el que llegué a la trocha estaba contaminado con el virus. Llegué enferma, pero gracias al comandante Chávez me curé, estoy sana, vivita y coleando.

(Testimonio María Francia, 38 años, Caracas, 17 de junio de 2020).

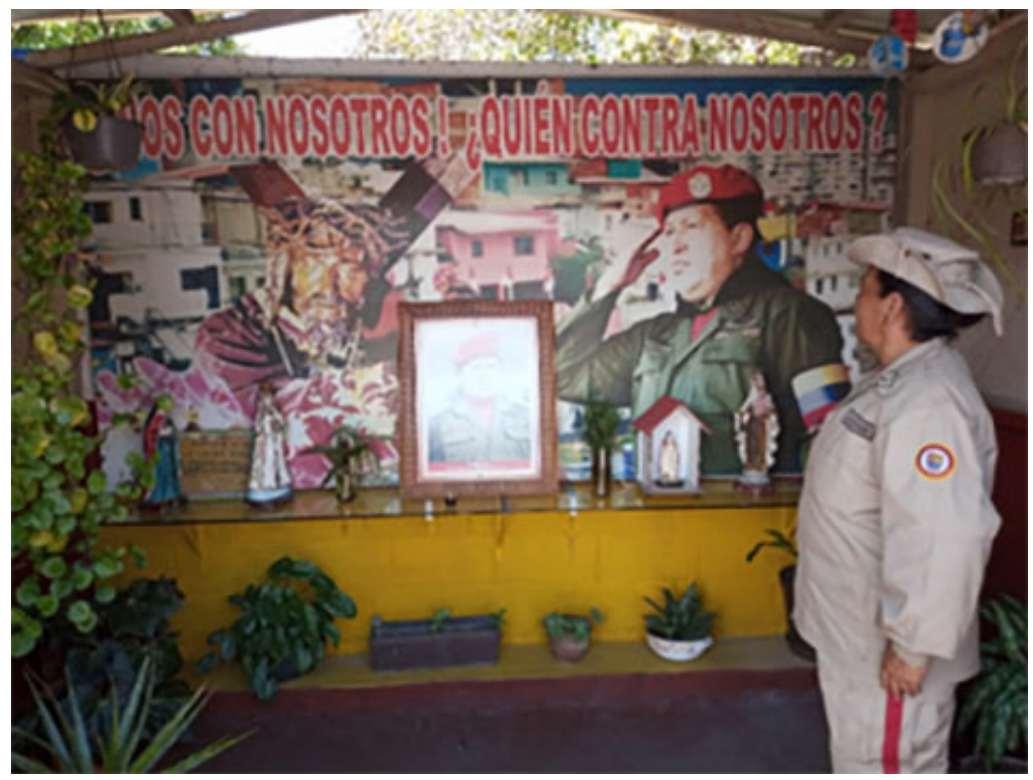

Elizabeth Torres, guardiana de la capilla (Fotografía del autor, 17 de junio de 2020). 
En visitas previas a la pandemia siempre encontré relatos de curaciones por parte de la intercesión divina de Chávez. También ha demostrado eficiencia principalmente en la adjudicación de viviendas y trabajo, por lo que decenas de personas suben mensualmente a dejar cartas en la capilla de San Hugo Chávez. Mis observaciones en el 23 de enero dan cuenta que, para pedir un favor, es necesario primeramente visitar la capilla, encender una vela y estar en contacto con el presidente. María del Carmen, quien sufrió un accidente de tránsito que la dejó por meses en una silla de ruedas, afirmó que el primer paso es creer ciegamente en el "comandante eterno y supremo", rezar la oración, visitarle en el 23 y prenderle una velita cada vez que se pueda.

Es necesario, según me contó, tocar el busto de Chávez que está en la capilla, el cual "transmite una energía indescriptible". Luego, es recomendable caminar unos 200 metros hasta el Cuartel de la Montaña, donde reposan los restos del presidente, pero en ese lugar está prohibido manifestar abiertamente devociones, no se pueden dejar flores ni encender velas. Durante la pandemia, las visitas al Cuartel de la Montaña estuvieron prohibidas, razón por la cual, los creyentes solo se acercaban a la capilla y no lograron cumplir el circuito. María del Carmen me relató su historia y milagro:

Los médicos me operaron varias veces, estuve años en silla de ruedas, me decían que yo no caminaba más nunca, aunque me mantenía en terapias. Dios mío no iba a caminar más nunca. Yo tengo dos hijos y dije no puedo estar postrada toda la vida. Siempre fui fiel creyente del comandante Chávez, fue mi líder político y ahora es mi líder espiritual. Había escuchado de la capilla pero nunca había venido, también escuché de varios milagros, así que le dije a mi esposo que me trajera. Conseguí la oración al comandante eterno y supremo y comencé a pedirle con mucha fe. Me traían todas las semanas, eso fue como en mayo de 2015. El accidente fue en diciembre de 2014. Siempre me mantuve positiva y asistía a mis terapias con los médicos cubanos que son muy buenos, ellos me alentaban, pero el resto me decía que yo no caminaba... A los tres meses dejé la silla de ruedas, me levanté y usé andadera. Ya eso fue un milagro. Reafirmé mi fe al comandante Chávez. Hablaba con él con mayor fuerza. A toda hora repetía su oración, me la aprendí de memoria. (Testimonio María del Carmen. Caracas, 7 de marzo de 2018)

Elizabeth Torres también me informó que por dos años visitó mensualmente al 23 de enero una señora colombiana, a dar gracias porque San Hugo Chávez del 23 le hizo un favor. Su hijo fue secuestrado por la guerrilla colombiana, no tenía como pagar rescate. Ella le ofreció un corazón de rosas rojas si el muchacho llegaba sano y salvo a casa, "y llegó a la casa. Chávez le hizo el milagro". 
Otros creyentes en la fuerza suprahumana del comandante Chávez como el sargento Moncada, quien fue electo constituyentista en los comicios del 30 de julio de 2017 en representación de los jubilados y pensionados, no duda que llegó a esa instancia con la ayuda de Chávez, quien, para él, es un muerto poderoso. Le adjudica poder, pero se niega a llamarlo santo.

Te voy a decir una vaina, yo no quiero convertir a Chávez en un santo, pero tiene poder, es un muerto con poder. Siempre le pido en las mañanas, en las noches antes de acostarme, en todo momento. Yo le dije a Chávez que quería ser constituyentista, que me permitiera recoger las firmas para postularme como candidato a la Asamblea Nacional Constituyente y representar a las bases, al pueblo. En dos días recogí las 500 firmas que necesitaba para ser candidato. Soy representante de los jubilados y pensionados en la Asamblea Nacional Constituyente. Me puso ahí Chávez.

(Testimonio sargento Moncada, Caracas, 2018)

\section{El heredero de Bolívar}

Venezuela es un país donde es común el culto a los muertos. Familiares fallecidos, figuras carismáticas y héroes de la patria como Simón Bolívar, son visibles en altares domésticos acompañando a vírgenes y santos oficiales del catolicismo. Desde la aparición pública de Chávez, en sectores populares de tradición católica, pentecostales evangélicos y espiritistas del culto a María Lionza ${ }^{5}$, comenzaron a verle como el heredero del Libertador Simón Bolívar.

La antropóloga Yolanda Salas $(1987,2005)$ hizo referencia a que Bolívar fue mitificado como reivindicador de las clases que están fuera de las esferas del poder, por lo que se convirtió en mensajero divino, que abre caminos y genera sentimientos mesiánicos en sus admiradores que esperaban una nueva liberación, por lo que en la década de 1990 hubo expectativa por la llegada de un nuevo mesías y para muchos creyentes, ese nuevo enviado fue el comandante Chávez.

Igualmente, Salas relató que, en el imaginario popular, Bolívar está dotado de poderes para proteger y velar por las necesidades del pueblo venezolano y esa idea también se extendió y afianzó en tono a la imagen de Chávez, quien, para muchos, a pesar de su desaparición física, sigue siendo el presidente desde otro plano. Así es llamado por algunos interlocutores como "el santo-presidente", por lo que se le pide además de salud y protección, viviendas, trabajo, ayudas sociales y "protección

5 Religión venezolana cuya figura central es la reina María Lionza. Se caracteriza por invocaciones por parte de médiums a espíritus agrupados por cortes, de acuerdo a su especialización, origen étnico u oficio. En este sentido, María Lionza es una deidad, que, de acuerdo a la tradición oral, fue una princesa indígena que habitó en la montaña de Sorte -estado Yaracuy-, epicentro de quienes la veneran. 
para Maduro", consolidando de esta forma un régimen de confianza con la figura sacralizada del líder de la revolución bolivariana.

En este contexto cobra importancia el culto a María Lionza, adoración a la diosa que lleva este nombre y a un gran número de espíritus que conforman su extenso panteón. Precisamente, la veneración a María Lionza se convierte en un antecedente cultural importante que de alguna manera permite sacralizaciones de héroes de la patria, médicos prominentes, estudiantes, curanderos, parturientas, esclavos africanos, indígenas, políticos, jóvenes bandoleros, militares y hasta don juanes, éstos últimos galanes de telenovelas quienes disfrutaban cortejando a las mujeres. Dependiendo de las dinámicas político-sociales del país ingresan o salen espíritus de las cortes.

Bolívar, por ejemplo, ocupa un lugar importante dentro del grupo de divinidades marialionceras, en especial de la corte Libertadora, caracterizada por espíritus que realzan el nacionalismo y defensa de la patria. Por otro lado, también es objeto de veneración en todo el territorio nacional al margen de estas prácticas espiritistas. Lo mismo ocurre con la figura del expresidente Hugo Chávez. Además de la veneración en sectores populares, hay evidencia de su invocación por parte de médiums, consolidando otras formas en las que Chávez interviene en el mundo de los vivos.

En este sentido, la génesis del culto a Chávez tiene sus conexiones con el culto a Simón Bolívar. Pollak-Eltz (2000) afirma que un grupo considerable de marialionceros tras la intentona golpista del cuatro de febrero de 1992, consideró al comandante Chávez como la reencarnación de Bolívar y este a su vez, la reencarnación del cacique Guaicaipuro, quien luchó férreamente contra el dominio español en tiempos de la conquista.

Por otra parte, el periodista Oscar Yánez (2000) quien entrevistó en diversas oportunidades al comandante Chávez, afirmó que el proyecto bolivariano del presidente estaba inspirado en mensajes de ultratumba, lo que, a su juicio, no puede tomarse como indicio de inferioridad intelectual, porque grandes hombres de la historia creían y creen fielmente que algunos pensamientos les son dictados desde el otro mundo. Incluso, llegó a considerar que ese gobierno era "espiritista", es decir, Chávez ejerció el poder por orientación de muertos que operan en la cotidianidad de los vivos.

En sintonía con Yánez y los estudios de Yolanda Salas, el español Miguel Ferrándiz (2004) hizo un seguimiento del espíritu de Bolívar incorporado a médiums marialionceros, precisamente en la década en que Hugo Chávez protagonizó el levantamiento militar. Durante su rastreo del espíritu del Libertador vio reflejado hasta qué punto la crisis económica, política e ideológica en la que estaba sumida Venezuela en esos años se filtró a la corporalidad del culto, convirtiendo el trance en un espacio de crítica social y de duelo popular por el desmoronamiento de un ideal político (Ferrándiz 2004:27-28). 
No es casual entonces, que las reflexiones del espíritu de Bolívar observadas por Ferrándiz sirvieran de telón para que una vez materializado el intento de golpe por parte de Hugo Chávez contra el presidente Carlos Andrés Pérez en 1992, se iniciara un proceso de sacralización en torno a la figura del comandante Chávez, como lo reza la plegaria observada por Taussig, en la que se le pide que libere al pueblo del presidente de la época. Se observan en estos planteamientos, esquemas en los que entremezcla la religiosidad popular y la política, debido a la relación inmanente con la figura sacralizada de Chávez.

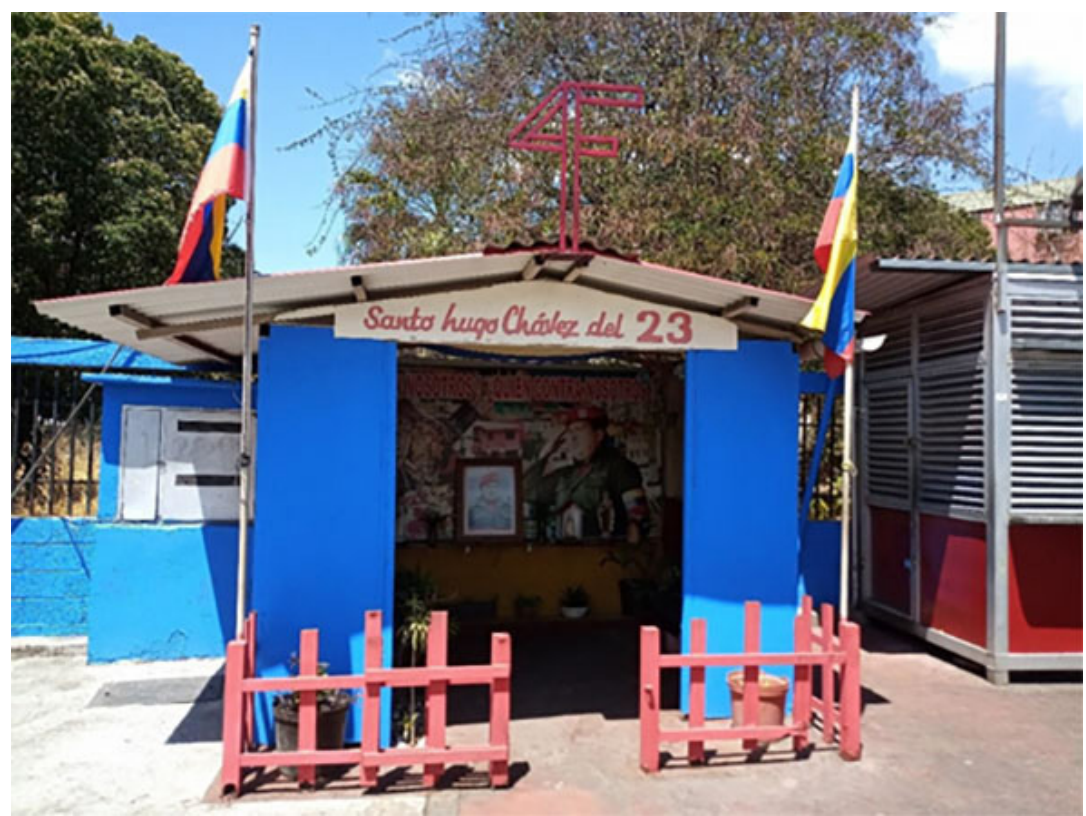

La capilla a San Hugo Chávez del 23 en la actualidad (Fotografía del autor, 17 de junio de 2020).

\section{Cosmopolítica en el 23 de enero}

Las relaciones inmanentes con lo sagrado observadas en el 23 de enero, donde los creyentes en los poderes de Hugo Chávez no separan el campo religioso de la política, abren espacios para reflexiones sobre la cosmopolítica. La propuesta de Stengers (2014) resulta de gran utilidad para comprender cómo las fuerzas suprahumanas y mágicas se relacionan con el mundo de lo humano, en los que un grupo de personas pertenecientes a sectores populares urbanos, rinde culto al líder de la revolución bolivariana y, a su vez, reafirman el compromiso político de mantener vivo el proyecto chavista, incluso en tiempos de pandemia.

En Venezuela existe desde hace muchísimo tiempo una fuerte relación con espíritus de bandoleros, médicos, estudiantes y parteras; también ánimas, familiares 
fallecidos y grupos de espíritus de la religión de la reina María Lionza. Como ya lo hemos afirmado en diversas oportunidades, los muertos siguen activos en el mundo de los vivos, incluyendo su participación en el quehacer político. Es decir, lo "suprahumano" incide en las decisiones de la gente, articulando vínculos con deidades que nos hacen pensar en un cosmos alternativo para entender estas prácticas.

La cosmopolítica remite a mundos múltiples, por lo que las comprensiones ontológicas de la ciencia occidental serían una entre otras posibles, pero no las únicas. Es decir, se abre el camino para otras alternativas y formas de relacionarse con lo sagrado y de hacer política, como ocurre en el 23 de enero. En este sentido, el prefijo cosmos no debe restringirse a lo humano, sino que debería abarcar y comprender la relación de las muchas formas de valor, concretas, heterogéneas y duraderas que componen la realidad, incluyendo a los ancestros, seres suprahumanos (vivos y muertos) que vienen a mediar entre los humanos, como ocurre en el caso de Chávez, considerado por algunos un santo, un ser vergatario y un muerto poderoso.

Vemos entonces que la cosmopolítica trae una visión distinta de la política y desde las ciencias sociales debe ponerse atención a esos compromisos entre saberes y mundos distintos, posibles y comunes. En el caso venezolano, por ejemplo, observamos como los espíritus alteran prácticas, relaciones entre humanos y muertos, y transforman la composición material del mundo, generando tensiones, nuevas relaciones en el ámbito social y hasta participación activa en tiempos de elecciones como ocurrió en los comicios legislativos del pasado seis de diciembre de 2020. En estos comicios, por ejemplo, los creyentes usaban con insistencia la imagen de Hugo Chávez, "a quien le debemos lealtad".

Durante la campaña electoral algunos devotos/simpatizantes visitaban a la capilla para "conversar con Chávez y garantizar la victoria socialista". Ven con buenos ojos la revolución bolivariana y consideran que el expresidente Chávez no ha muerto sino trascendió y cambió de paisaje, sigue gobernando desde otro plano. Por esta razón le piden viviendas, trabajo, operaciones quirúrgicas y hasta "iluminación para Maduro para que no siga metiendo la pata y lo haga quedar mal", como me lo manifestaron varios entrevistados, evidenciando que no todos los seguidores del llamado proceso revolucionario son acríticos y avalan las calamidades que enfrenta desde hace años el país. Reconocen que el Gobierno actual ha cometido graves errores y piden a San Hugo Chávez para que guíe a quien consideran su representante, porque desde su perspectiva, el presidente sigue siendo el comandante Chávez.

Vemos entonces que la capilla se transforma en la oficina presidencial del Palacio de Miraflores. La gente deja cartas, solicitudes y regalos en agradecimiento a los favores concedidos. Si bien la mayoría de los devotos y simpatizantes afirman apoyar electoralmente a Nicolás Maduro, algunos manifiestan que se están cometiendo errores graves y que, el funcionamiento de las grandes Misiones creadas por Chávez, no funcionan desde hace tiempo, "porque Maduro está siendo engañado por gente mala". 
En contextos como el de Venezuela, azotados desde hace tiempo por crisis económicas y malos gobiernos, quienes piden favores a entidades sacralizadas por el pueblo, por lo general son personas precarizadas por gobiernos neoliberales que no fueron capaces de satisfacer necesidades básicas. Sin embargo, este caso las observaciones y/o críticas provienen de los mismos devotos/simpatizantes que apoyan a la revolución bolivariana, quienes piden a Chávez que "ayude a Maduro", evidenciando que algo está pasando y que no están siendo beneficiados por los programas sociales de otrora.

Vemos entonces, en términos de Pávez y Kraushaar (2010), citado por Hernández (2018) se va estructurando sobre la imagen milagrosa de Hugo Chávez, la de un presidente de una teocracia biopolítica que dispensa protección de la vida e interviene con milagros y favores sobre personas precarizadas que no están recibiendo atención "como antes", pero se mantienen fieles al ideario chavista, a pesar de las debilidades del propio proceso revolucionario y a las tensiones generadas por las protestas de sectores de oposición escenificadas en 2014 y 2017.

En este sentido y por lo inobjetable de la presencia de los muertos en la cotidianidad venezolana, vemos como personas fallecidas se hacen tan presentes como los vivos, gobiernan e inciden en decisiones de relevancia. Las cortes marialionceras, los santos populares, ánimas y espíritus de la sábana, son muestra de la vigencia cosmopolítica en estas tierras y de cómo los muertos se consolidan, hablan, opinan y participan en política.

En el caso de Chávez, su presencia es tan importante en sectores populares urbanos que desde el Gobierno se ha capturado iconografía considerada sagrada por la gente, colocando el acento en las posibilidades que se abren entre potenciales votantes y candidatos del Partido Socialista Unido de Venezuela (PSUV), tratando de incidir y legitimar las decisiones que se toman en las urnas electorales. Sobre todo, en momentos en los que las elecciones parlamentarias del seis de diciembre de 2020 han sido severamente cuestionadas por un gran sector de la población ${ }^{6}$.

\section{El vínculo con Chávez: lectura antropológica}

Las miradas relacionales de lo religioso son una perspectiva que articula el plano trascendente e inmanente, y son, por lo tanto, un buen punto de partida para entender las formas en que personas de las periferias urbanas, con bajos niveles de ingreso, instrucción y escaso acceso a los bienes culturales legítimos viven lo religioso. En estos contextos, la presencia y el contacto con santos y otras figuras suprahumanas forma parte de la cotidianidad?

6 El PSUV es el partido oficial de gobierno, fundado por Hugo Chávez en diciembre de 2006. Agrupa a diversas fuerzas revolucionarias.

7 Desde nuestra perspectiva consideramos que todavía sería necesario una reflexión en profundidad sobre cómo la tradición relacional del enfoque de Hubert y Mauss (1970) puede vincularse con la perspectiva de la religión vivida (Ammerman 2007; Frigerio 2018; Orsi 2005; Tweed 2015). Entendemos que entre estas posiciones teóricas existen más continuidades que diferencias. 
Esta situación se evidencia en el caso venezolano y otros países de Latinoamérica, en los cuales es común apreciar santos, muertos poderosos, ánimas, héroes de la patria y familiares difuntos con licencia para intervenir en la rutina diaria de los vivos. Con estos seres la gente explora nuevos contratos e intercambios a cambio del pago de promesas, práctica que se ha convertido en una forma moderna de sacrificio, en donde también entran en juego los discursos rituales u oraciones adoptadas por los creyentes.

Es así como en el caso que me ocupa, un proceso que involucra religión y la sacralización de un líder político fue adquiriendo visibilidad en el espacio público a través de la capilla construida en el 23 de enero y las estatuitas de Hugo Chávez a la venta en perfumerías espiritistas ubicadas en la Avenida Baralt de Caracas, que se siguen vendiendo a pesar de la pandemia.

También se ha ido construyendo como lo evidencia el trabajo etnográfico, un discurso que resalta la potencia a la hora de hacer milagros; en especial, la atención de casos prácticos relacionados a necesidades básicas como la adquisición de una vivienda, trabajo, pensiones y salud, favores que lo consagran como el "santo-presidente", categoría nativa con la cual algunos devotos se refieren al comandante Chávez.

La sacralización de Hugo Chávez nos lleva a revisar posiciones teóricas sobre la problemática de los santos populares en América Latina. Carozzi (2003, 2004) y Martin (2007) hacen un recorrido que muestra la porosidad entre prácticas religiosas y otras de la vida cotidiana como la música, en las cuales se sacraliza a figuras que de alguna manera son consideradas excepcionales, personas que durante su vida ejercieron un poder e influencia que para algunos es fuera de lo común, en la que se pliega la excepcionalidad de sus propias áreas con lo sagrado. Este tipo de análisis ha sido realizado también con otros personajes excepcionales. El fenómeno de médicos famosos que, una vez muertos, se convierten en figuras sagradas parece relativamente habitual en América Latina. En el caso de la medicina venezolana es sintomático el del doctor José Gregorio Hernández analizado por Ferrándiz (2004).

En lo que a políticos se refiere, la estadounidense J.M Taylor (1981) estudió las asociaciones que simpatizantes peronistas elaboraron sobre Eva Perón, convertida en un signo de proximidad con lo divino, poseedora de poderes similares a los santos cristianos. En Venezuela, Rivas Aguilar (1989), reconstruyó la biografía mítica de Alberto Carnevali, gobernador del estado Mérida entre octubre de 1945 y diciembre de 1946, quien es venerado en la zona andina donde tiene fama de ser un muerto muy poderoso ${ }^{8}$.

En todos estos casos se observan manifestaciones profundas en las que interviene toda la subjetividad del devoto en relación con la figura sacralizada, lo que

8 Alberto Carnevali fue un político y periodista venezolano opositor al dictador Marcos Pérez Jiménez quien gobernó Venezuela entre 1952 y 1958. Murió en 1953, encarcelado y enfermo de cáncer. Sus devotos afirman que fue asesinado por el régimen. En 1980 su tumba fue abierta y el cuerpo se mantenía intacto, señal que ratifica, según los creyentes, que no era cualquier muerto. 
implica procesos de identificación, auto-entrega, confianza y amistad entre los fieles y la figura suprahumana. Esta devoción de acuerdo con Menezes (2009), se inicia cuando se escucha sobre el poder y las habilidades del santo/muerto poderoso y se mide la capacidad de respuesta una vez que se pide un favor que, al ser concedido, va estructurando narrativas sobre su forma de operar en el mundo de los vivos, como ocurre en la actualidad con la figura de Chávez.

Calavia (2009) hace aportes relevantes sobre el vínculo que establecen los creyentes con entidades suprahumanas. El autor destaca que por lo general en las religiones hegemónicas se dibuja el contrato entre Dios y el devoto a una distancia equivalente a la que existe entre sujeto-objeto, mientras que, por el contrario, en el culto a los santos -vistos históricamente con reticencia por la misma iglesia católicase establece una relación con formas similares a las que rigen la sociabilidad común, es decir, entre sujetos sin la lejanía impuesta por la modernidad entre hombres y seres sagrados como también lo ha expuesto Martín (2007) al hablar de prácticas de sacralización.

La relación con Dios es distinta, está por delante un protocolo especial que marca su alejamiento con respecto a la sociabilidad común. Vemos entonces que los santos pasan a formar parte de un sistema de redes en donde se convierten en una especie de mediadores. No obstante, durante el trabajo interactué con personas que le dan cierta autonomía a la figura de Hugo Chávez, es decir, para algunos, si bien es un enviado divino, no debe pedir permiso a Dios para actuar y conceder favores porque es un ser vergatario, único, especial y tiene la gracia divida para operar en el mundo de los vivos. Para otros, es un muerto muy poderoso que actúa por su cuenta, lo que nos lleva a analizar la problemática sobre el tipo de vínculo que establecen los devotos/solicitantes en un país donde además de santos populares también se le adjudican favores a las ánimas y a los héroes de la patria como Simón Bolívar.

En el caso de los santos populares y/o muertos poderosos, la convivencia rutinaria con los milagros le asigna ese principio o atributo sin la anuencia de la jerarquía eclesiástica. En los sectores populares se apropian y reinterpretan símbolos que de alguna manera quiebran el monopolio de la interpretación, llevando a los altares a sus propios santos como ocurre con San Hugo Chávez. Estos vínculos se alejan del modelo que supone salvación, pues en este caso los creyentes buscan solucionar aspectos rutinarios de la vida que la propia revolución bolivariana tiene dificultades para resolver.

Esta es la razón por la que sugerimos acompañar, como lo manifesté anteriormente, la categoría devoto con la de solicitante, es decir: devoto/solicitante. Este término pone en primer plano la demanda y la relación, así como intercambios pragmáticos establecidos con los muertos. Flores Martos (2014) citando a Losonczy (2001:11) expone que las diferencias entre las nociones de devoto/fiel señalan la separación entre una perspectiva centrada en la salvación para el más allá, y una actitud religiosa de recurso hacia entidades suprahumanas, en torno a problemas 
cotidianos. Esta diferencia viene a constituir una línea divisoria entre una religiosidad teológica y una más popular, en contradicción con parte del dogma católico.

De esta forma, podremos comprender estas subjetividades que se fortalecen en tiempos complicados como la pandemia por Covid-19, tiempo en el cual, los creyentes en San Hugo Chávez siguen visitándolo en la capilla, visten camisetas rojas alusivas al santo, exhiben tatuajes, portan rosarios, aretes y otros accesorios con la figura del comandante, porque de acuerdo a su cosmovisión: "Chávez vive".

\section{A manera de conclusión}

Estas formas de vincularse con Hugo Chávez y que se profundizan en tiempos de Covid-19, evidencian un imaginario en el que la muerte juega un rol importante en la vida de los vivos, estableciéndose una red de relaciones casi humana que involucra sujetos comunes con una serie de figuras sagradas. En Venezuela estos vínculos forman parte del día a día y permiten llevar a los altares domésticos a familiares fallecidos, personas carismáticas, héroes de la patria y políticos como el propio comandante Hugo Chávez.

El aspecto relacional que abordamos en este artículo, permite ubicar como religioso a los distintos vínculos que establecen los devotos/solicitantes y simpatizantes con la figura sacralizada de Hugo Chávez. Estas relaciones establecidas entre humanos y el "santo-presidente", no precisan estar legitimados socialmente como tales, ni suceder dentro de determinados grupos socialmente legitimados como religiosos, ni en los contextos que éstos estipulan como correctos para actividades religiosas, ni estar propuestos por determinado tipo de agente religioso socialmente legitimado. Son parte de la cotidianidad de la gente, relaciones inmanentes con el comandante Hugo Chávez que, como ocurre en el 23 de enero, parece no separar los campos político/religioso.

Siguiendo este supuesto teórico, el culto a San Hugo Chávez del 23 es visto como estas nuevas formas de religiosidad que vienen a enriquecer la diversidad religiosa invisibilizada por nuestros preconceptos. Este culto permite entonces ver la religión por fuera de las religiones, por fuera de las instituciones y los grupos usualmente considerados como tales. Permite ver la religión con otras posibilidades, en donde sin importar el grado de complejidad, se muestren o se hagan evidentes las relaciones entre los humanos y los seres suprahumanos que postula como relevantes, en especial, en tiempos convulsos como los que experimentamos por la pandemia. También permite ver las formas de vivir la religión y la política como partes de una misma esfera, permitiendo relaciones inmanentes con lo sagrado en donde la porosidad entre campos se hace presente. 


\section{Referencias bibliográficas}

AMMERMAN, N. (2007), Everyday religion: Observing modern religious lives. Oxford: Oxford University Press.

CALAVIA, O. (2009), “O que os santos podem fazer pela antropología?". Revista Religión y Sociedad, vol. 29: 198-219.

CAROZZI, M. (2003), "Carlos Gardel, el patrimonio que sonríe". Horizontes Antropológicos, n 20: 59. 82.

CAROZZI, M. (2004), "Rituales en el horario central: sacralizando a Gardel en los homenajes televisivos". Ciencias Sociales y religión, n 6: 11-29.

FERRÁNDIZ, F. (2004), Escenarios del cuerpo. Espiritismo y sociedad en Venezuela. Bilbao: Publicaciones Universidad de Deusto.

FLORES MARTOS, J (2014), "Iconografías emergentes y muertes patrimonializadas en América Latina: Santa Muerte, muertos milagrosos y muertos adoptados”. AIBR Revista de Antropología Iberoamericana, $\mathrm{n}^{\circ}$ 2: 115-140.

FRIGERIO, A. (2018), "iPor qué no podemos ver la diversidad religiosa?: Cuestionando el paradigma católico-céntrico en el estudio de la religión en Latinoamérica”. Cultura y representaciones sociales, $n^{\circ}$ 24: 51-95.

HERNÁNDEZ, L. (2018), "El culto a Hugo Chávez en Venezuela: isanto, ser vergatario o muerto poderoso?" Ciencias Sociais e Religiao, n 28: 114-128.

HUBERT H. \& MAUSS M. (1970), "De la naturaleza y de la función del sacrificio". In: Lo sagrado y lo profano. Obras I. Barral Editores. Barcelona.

MARTÍN, E. (2007), "Gilda, el ángel de la cumbia". Religiao $\mathbb{E}$ Sociedade, vol. 27, n 2: 30-54.

MENEZES, R. (2009), "San Antonio de Rio de Janerio: dimensiones de la santidad y devoción". In: Catolicismo Plural. Dinámicas contemporáneas. Rio de Janeiro: Vozes.

LOSONCZY, A (2001), "Santificaciones populares de los Muertos en cementerios urbanos colombianos". Revista colombiana de Antropología, n 37: 6-23.

ORSI, R. (2005), Between Heaven and Earth: The religious worlds people make and the scholars who study them. Princeton: Princeton University Press.

PÁVEZ, J. \& KRAUSHAAR, I. (2010), "Nombre, muerte y santificación de una prostituta. Escritura y culto de Botitas negras". Revista de Antropología Iberoamericana, n 3: 447-492. Chile.

POLLAK-ELTZ, (2000), Religión y política en Venezuela. Ponencia presentada en el Congreso Internacional sobre Religión. Buenos Aires, Argentina.

RIVAS, A. (1989), Alberto Carnevali, pasión de libertad. (Escritos). Tomo I. Mérida: Universidad Popular Alberto Carnevali. Acción Democrática.

SALAS, Y. (1987), Bolívar y la historia en la conciencia popular. Caracas: Instituto de Altos Estudios de la Universidad Simón Bolívar.

SALAS, Y. (2005), "La dramatización social y política del imaginario popular. El fenómeno del bolivarismo en Venezuela". Cultura, política y sociedad. Perspectivas latinoamericanas. Daniel Mato (Ed). Buenos Aires: CLACSO.

STENGERS, I. (2014), "La propuesta cosmopolítica". Revista Pleyáde, n 14: 17-41.

TAUSSIG, M. (2015), La magia del Estado. Ciudad de México: Siglo XXI Editores.

TAYLOR, J. M. (1981), Evita Perón. Los mitos de una mujer. Buenos Aires: Editorial Belgrano.

TWEED, T. (2015), "After the quotidian turn: Interpretive categories and scholarly trajectories in the study of religion since 1960s". The Journal of Religion, vol. 95, $\mathrm{n}^{\circ}$ 3) 361-385.

YÁNEZ, O. (2000), Gobierno espiritista. Caracas, Diario El Universal. 
Luis Alonso Hernández* (prof.luisalonsohernandez@uam.edu.ve)

* Becario de finalización de Doctorado del Consejo Nacional de Investigaciones Científicas y Técnicas de la república Argentina (CONICET), con lugar de trabajo en el Instituto de Investigaciones de la Facultad de Ciencias Sociales de la Universidad Católica Argentina (UCA). Profesor Asociado e investigador en el área de Antropología Cultural del Centro de Investigaciones de la Facultad de Ciencias Económicas y Sociales de la Universidad Arturo Michelena (CIFACES-UAM) Carabobo-Venezuela. Profesor Asociado en la Universidad de Carabobo, Carabobo-Venezuela. Magíster en Antropología Social, por la FLACSO-Argentina. 


\section{Resumen:}

\section{Cosmopolítica, religiosidad y pandemia en Venezuela}

El culto al presidente Hugo Chávez en sectores populares urbanos de la capital venezolana se ha reforzado en medio de la pandemia. Un trabajo de campo realizado durante las semanas de flexibilización decretadas por el gobierno de Venezuela, evidenció que los creyentes visitaban la capilla consagrada a San Hugo Chávez del 23, ubicada en la parroquia 23 de enero de Caracas, para pedir protección, viviendas, intervenciones quirúrgicas y dar gracias por asuntos relacionados a la salud, incluyendo sanaciones entre contagiados por la Covid-19. En este sentido, estamos frente a una forma de religiosidad en la que los creyentes buscan resolver problemas de la vida cotidiana, estableciendo un fuerte vínculo sagrado con la imagen sacralizada de Chávez, relación inmanente que parece no separar lo sagrado de lo político, es decir, lo "cosmopolítico". Por otra parte, se aprecia cómo desde el discurso oficial, se refuerza la imagen de Chávez como el salvador/protector del país, razón por la cual, Venezuela tendría los índices más bajos de contagiados de toda América Latina.

Palabras clave: Venezuela; Hugo Chávez; pandemia; Covid-19; cosmopolítica

\section{Resumo:}

\section{Cosmopolítica, religiosidade e pandemia na Venezuela}

O culto ao presidente Hugo Chávez nos setores populares urbanos da capital venezuelana foi reforçado em meio à pandemia. Um trabalho de campo realizado durante as semanas de relaxamento decretadas pelo governo da Venezuela, mostrou que os fiéis visitaram a capela consagrada a San Hugo Chávez no dia 23, localizada na paróquia 23 de Enero de Caracas, para solicitar proteção, habitação, intervenções cirúrgicas e agradecer por questões relacionadas à saúde, incluindo curas entre as pessoas infectadas pela Covid-19. Nesse sentido, estamos diante de uma forma de religiosidade em que os fiéis buscam resolver os problemas do cotidiano, estabelecendo um forte vínculo sagrado com a imagem sagrada de Chávez, uma relação imanente que não parece separar o sagrado do político, isto é, o "cosmopolítico". Por outro lado, aprecia-se como, a partir do discurso oficial, se reforça a imagem de Chávez como salvador/protetor do país, razão pela qual a Venezuela teria os menores índices de infectados de toda a América Latina.

Palavras-chave: Venezuela; Hugo Chávez; pandemia; Covid-19; cosmopolítica 


\section{Abstract:}

\section{Cosmopolitics, religiosity and pandemic in Venezuela}

The cult of President Hugo Chávez in popular urban sectors of the Venezuelan capital has been reinforced in the midst of the pandemic. Fieldwork carried out during the weeks of relaxation decreed by the government of Venezuela, showed that the believers visited the chapel consecrated to San Hugo Chávez on 23, located in the parish 23 de enero de Caracas, to request protection, housing, surgical interventions and give thanks for health-related matters, including healings among those infected by Covid-19. In this sense, we are facing a form of religiosity in which believers seek to solve problems of daily life, establishing a strong sacred link with the sacred image of Chávez, an immanent relationship that does not seem to separate the sacred from the political, that is, , the "cosmopolitical". On the other hand, it is appreciated how from the government discourse, the image of Chávez as the savior / protector of the country is reinforced, which is why Venezuela would have the lowest rates of infected in all of Latin America.

Keywords: Venezuela; Hugo Chávez; pandemic; Covid-19; cosmopolitics 